\title{
REPORTS
}

Published: 2020-11-30

Ivan Urits, MD

Omar Viswanath, $\mathrm{MD}^{2-4}$

Vwaire Orhurhu, MD ${ }^{1}$

Alan D. Kaye, MD, PhD

Cyrus Yazdi, MD ${ }^{1}$

\section{Case at a Glance: Radiographic Findings of a Symptomatic Lumbar Synovial Cyst Causing RADICULOPATHY}
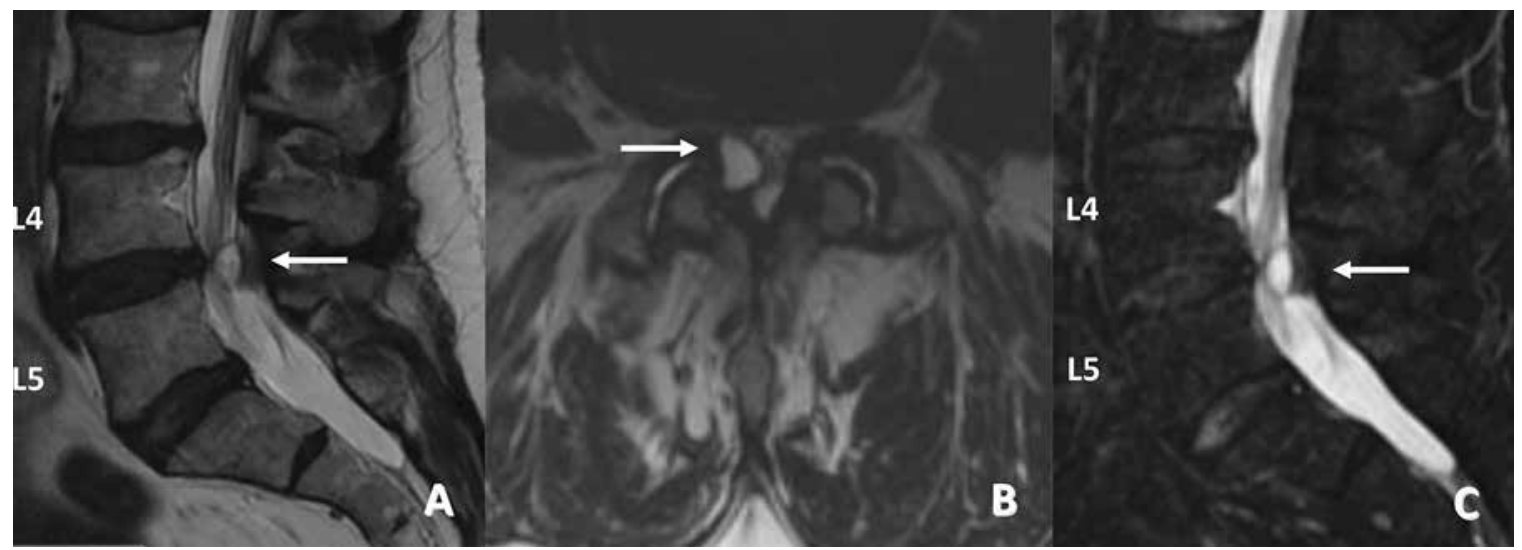

Fig. 1. A) T1 sagittal computed tomographic (CT) image demonstrating a synovial cyst causing significant crowding at the L4-L5 vertebral level. B) T2 axial cut demonstrating severe central canal stenosis. C) T2 sagittal CT image.

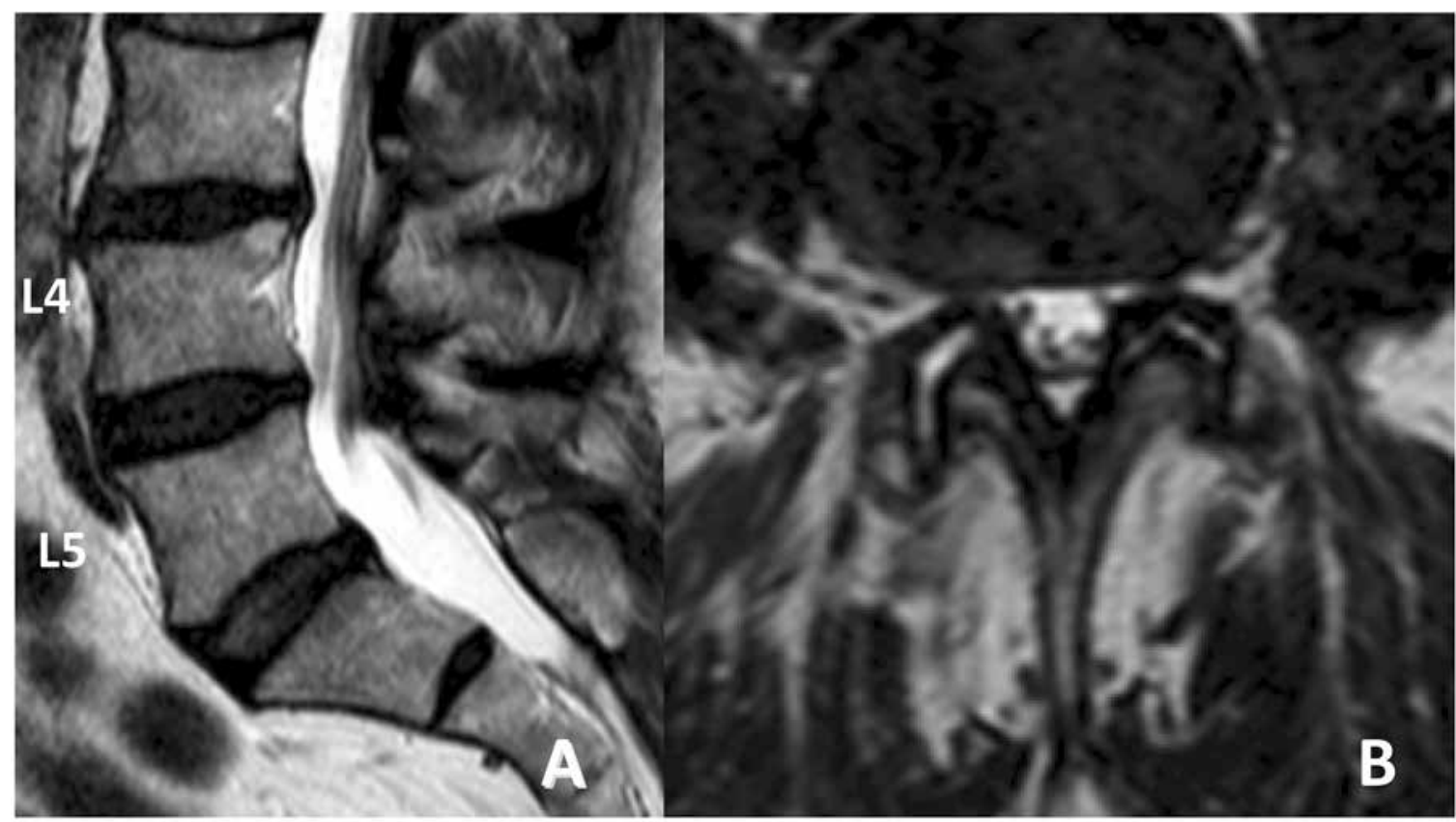

Fig. 2. A) T2 sagittal and $B$ ) axial CT images demonstrating no synovial cyst recurrence.

From: 'Department of Anesthesia, Critical Care, and Pain Medicine, Beth Israel Deaconess Medical Center, Harvard Medical School, Boston, MA; ${ }^{2}$ Valley Anesthesiology and Pain Consultants, Phoenix, AZ; ${ }^{3}$ Department of Anesthesiology, University of Arizona College of Medicine, Phoenix, AZ; ${ }^{4}$ Department of Anesthesiology, Creighton University School of Medicine, Omaha, NE; ${ }^{5}$ Department of Anesthesiology, Louisiana State University Health Sciences Center, New Orleans, LA

Corresponding Author: Ivan Urits, MD, E-mail: iurits@bidmc.harvard.edu

Disclaimer: There was no external funding in the preparation of this manuscript.

Conflict of interest: Each author certifies that he or she, or a member of his or her immediate family, has no commercial association (i.e., consultancies, stock ownership, equity interest, patent/licensing arrangements, etc.) that might pose a conflict of interest in connection with the submitted manuscript. 
Spinal synovial cysts originate from the facet joints of the spine and are observed most commonly at the L4-L5 vertebral level (1). Though not considered as a common cause of radicular back pain, spinal synovial cysts are increasingly diagnosed related to recent advances in magnetic resonance imaging (MRI) and computed tomography (CT) technologies (2). These radiographic images demonstrate the dramatic findings of a large synovial cyst causing moderate to severe central canal stenosis at the L4-L5 vertebral level (Fig. 1).

Our patient was a 60 -year-old male that presented with chronic low back pain and right lower extremity radiculopathy. Percutaneous aspiration and decompression may offer immediate symptom relief, however, symptomatic cyst recurrence causing back pain can be as high as $22 \%$ at 2 year follow-up (3). Surgical excision is recognized as the gold standard for the treatment of synovial cysts causing recalcitrant pain or neurological compromise (4-6). In our patient, a 22-gauge, 3-inch spinal needle was used to enter and aspirate the synovial cyst, under fluoroscopic guidance. Following the procedure, he reported excellent pain relief with complete resolution of his radicular symptoms. A follow-up lumbar spine MRI confirmed continued remission of his cyst at 6 months after his aspiration procedure (Fig. 2). In patients with nonremitting chronic low back pain, lower extremity radiculopathy, or lower extremity neurological deficits, CT and MRI are important diagnostic modalities for lumbar synovial cysts.

\section{REFERENCES}

1. Khan AM, Girardi F. Spinal lumbar synovial cysts. Diagnosis and management challenge. Eur Spine J 2006; 15:1176-1182.

2. Kouyialis AT, Boviatsis EJ, Korfias S, Sakas DE. Lumbar synovial cyst as a cause of low back pain and acute radiculopathy: A case report. South Med J 2005; 98:223-225.

3. Bydon A, Xu R, Parker SL, McGirt MJ, Bydon M, Gokaslan ZL, Witham TF. Recurrent back and leg pain and cyst reformation after surgical resection of spinal synovial cysts: Systematic review of reported postoperative outcomes. Spine J 2010; 10:820-826.
4. Lyons MK, Atkinson JL, Wharen RE, Deen HG, Zimmerman RS, Lemens SM. Surgical evaluation and management of lumbar synovial cysts: The Mayo Clinic experience. J Neurosurg 2000; 93:53-57.

5. Howington JU, Connolly ES, Voorhies RM. Intraspinal synovial cysts: 10-year experience at the Ochsner Clinic. J Neurosurg 1999; 91:193-199.

6. Banning CS, Thorell WE, Leibrock LG. Patient outcome after resection of lumbar juxtafacet cysts. Spine (Phila Pa 1976) 2001; 26:969-972 